\title{
INSTRUCTIONS TO THE AUTHORS
}

The journal "Ecological Engineering and Environment Protection" publishes original scientific papers and reviews on topical scientific problems from Bulgarian and foreign authors in English or Bulgarian in the fields of ecology, ecological engineering and environment protection.

1. The original scientific paper volume should be 4-10 pages (incl. the figures and tables), and the reviews should be up to 14 pages.

2. The materials should be written in Microsoft Word, font Times New Roman. Page format - A4; margins: top $2 \mathrm{~cm}$, bottom $3.5 \mathrm{~cm}$, left $2 \mathrm{~cm}$, right $2 \mathrm{~cm}$. The tables and figures (of good quality) should be at the respective place in the text. Expenses for printing colored figures should be covered by authors.

3. The title of the paper/review should be short and unabbreviated $(14 \mathrm{pt})$, reflecting the essentials of the investigation. The authors' names (first and family names in full - $11 \mathrm{pt}$ ) should be centered under the title. When the paper/review is in Bulgarian, the main text $(11 \mathrm{pt})$ should be preceded by the title and by an abstract (10 pt) in English of 5-10 rows and key words (10 pt) of no more than 1 row. When the paper/review is in English, in the end should be added the title and the abstract (11 pt) in Bulgarian. The abstract should summarize the main information about the paper and its contribution to the respective scientific topic.

4. The main text should be organized, for example, in the following order: Introduction, Materials and Methods, Results, as well as Discussion and Acknowledgments, if necessary.

5. All units of measurement should be written according to the International System of Measurements (SI). It is admissible to use (as additional information in brackets) also units of measurement that have established themselves in the respective areas.

6. The abbreviations used in the text should be explained under line or correspondingly in the text.

7. The authors' names and their papers or monographs included in the references should be cited in the text by numbers (in square brackets) corresponding to the referential ones.

8. The authors' names, scientific titles and position (at will) and address for correspondence (incl. telephone and e-mail) should be written (in Bulgarian and English) at the end of the text.

9. The materials should be submitted in electronic form. On demand, they should be presented also on paper carrier.

10. The materials not fulfilling the above requirements will not be considered.

11. Two anonymous specialists will review the materials submitted for publication. The materials not accepted will not be returned to the authors.

12. The editors keep the right to send back materials to the authors for amendments or rearrangement of the text according to the recommendations of the reviewers and the editorial board.

Arrangement of the references, examples:

A paper from a periodical:

1. Matsui S., D.E. Rounds, (article title), Life Sci., Vol. 10, 1971, 217-221.

A paper from a book:

3. De Mayer E., J. Quinard, (article title), In: Comprehensive Ecology (H. Frenkel-Conrat, R. R. Wagner, Eds.), Plenum Press, New York, 1978, 205-284.

A book:

6. Muller W. E. G., Waste Water Treatment, Pergamon Press, Oxford, 1980, 270 p.

A material printed in the proceedings of a science forum:

8. Gebresenbet G., D. Ljungberg et al., (article title), Proc. of the $4^{\text {th }}$ European Conf. in Precision Agr., Berlin, Germany, June 14-19, 2003, 25-31. 